\title{
PERCEPÇÃO DE CIDADÃOS DE UMA CIDADE DE MÉDIO PORTE EM RELAÇÃO AO USO DA BICICLETA COMO MODO DE TRANSPORTE
}

\section{Perception of citizens of a medium size city in relation the use of the bicycle as a transportation mode}

\author{
Mariana Grade Ricieri', Heliana Barbosa Fontenele², Carlos Alberto Prado da Silva Junior ${ }^{3}$ \\ Recebido em 07 de dezembro de 2016; recebido para revisão em 02 de fevereiro de 2017; aceito em 10 de março
} de 2017; disponivel on-line em 29 de março de 2017.

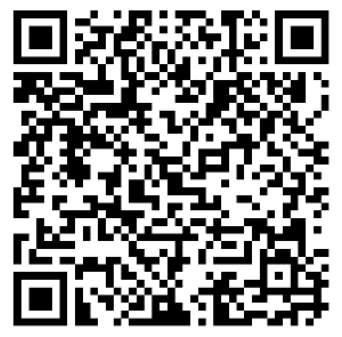

PALAVRAS CHAVE:

Bicicleta;

Transporte;

Mobilidade;

Análise de percepção;

Planejamento de

transporte.

\section{KEYWORDS:}

Bicycle;

Transportation;

Mobility;

Perception test;

Transport planning.

RESUMO: As cidades de porte médio no Brasil têm ocupado posição de destaque nos últimos anos. Porém, estas cidades têm seguido o mesmo caminho das cidades brasileiras mais populosas e negligenciado aspectos que garantam à manutenção das condições que favorecem investimentos públicos e principalmente privados. Em relação aos sistemas de transporte e logística, cada vez mais as cidades de porte médio têm se tornado dependente do uso do automóvel e evitado políticas de incentivo à mobilidade urbana sustentável. Desta forma, entender a percepção dos usuários dos sistemas de transporte urbano é fundamental para traçar medidas de incentivo para modos alternativos de viagens urbanas. $O$ objetivo deste estudo é apresentar uma análise da percepção dos usuários quanto aos modos de deslocamento urbano, principalmente a bicicleta e medidas específicas de incentivo ao uso deste modo não motorizado. A pesquisa foi realizada por meio de entrevistas com um questionário impresso. As respostas possibilitaram obter a opinião sobre o uso da bicicleta como modo de transporte, caracterizar o perfil socioeconômico dos entrevistados e simular um cenário em relação ao uso da bicicleta. Para o caso específico deste estudo ficou evidente que os entrevistados são favoráveis ao uso da bicicleta e uma parcela está disposta a usar o ciclismo desde que sejam implantadas medidas de incentivo.

ABSTRACT: The medium-sized cities in Brazil have occupied a prominent position in the last years. However, these cities have followed the same path of the most populous Brazilian cities and have neglected aspects that guarantee the maintenance of the conditions that favor public and private investments. Regarding transport and logistics systems, more and more medium-sized cities have become dependent on the use of the car and have avoided policies to encourage sustainable urban mobility. In this way, understanding the users' perception of urban transport systems is fundamental to outline incentive measures for alternative modes of urban travel. The objective of this study is to present an analysis of the perception of the users regarding urban displacement modes, especially the bicycle and specific measures to encourage the use of this non-motorized mode. The research was conducted through interviews with a printed questionnaire. The answers made it possible to obtain the opinion about the use of the bicycle as a mode of transportation, characterize the socioeconomic profile of the interviewees and simulate a scenario regarding the use of the bicycle. For the specific case of this study it was evident that the interviewees are favorable to the use of the bicycle and a portion is willing to use the bicycle provided that incentive measures are implemented.

* Contato com os autores:

'e-mail: marianagricieri@gmail.com (M. G. Ricieri )

Graduanda do curso de Engenharia Civil do Centro de Tecnologia e Urbanismo do Departamento de Construção Civil da Universidade Estadual de Londrina - UEL.

2e-mail: heliana@uel.br ( H. B. Fontenele)

Engenheira Civil, Professora Doutora do Curso de Engenharia Civil do Centro de Tecnologia e Urbanismo do Departamento de Construção Civil da Universidade Estadual de Londrina - UEL.

${ }^{3}$ e-mail: cprado@uel.br (C. A. P. Silva Junior )

Engenheiro Civil, Professor Doutor do curso de Engenharia Civil do Centro de Tecnologia e Urbanismo do Departamento de Construção Civil da Universidade Estadual de Londrina - UEL. 


\section{INTRODUÇÃO}

A implantação de infraestrutura e algumas medidas de incentivo ao uso da bicicleta têm se tornado frequente em algumas cidades brasileiras. A construção de ciclovias e ciclofaixas, bem como bicicletários, paraciclos e regras para compartilhamento de vias podem tornar mais visível e motivar o uso da bicicleta como modo de transporte. Porém, para viabilizar o uso do ciclismo no dia-a-dia é necessário entender a opinião da população sobre este modo de transporte. 0 Ministério das Cidades (Brasil, 2007) argumenta que muitos municípios brasileiros estão vivendo uma crise na mobilidade urbana. Esta crise pode estar sendo agravada pela falta de percepção e conscientização da população sobre viagens mais sustentáveis e que reduzam impactos negativos dos sistemas de transportes.

A questão do uso intensivo de transportes individuais motorizados em cidades brasileiras com crescente classe média consumidora tem contribuído para agravar problemas relacionados à mobilidade e a acessibilidade segundo Abreu et al. (2015). Por outro lado, para enfrentar estes problemas podem ser citados os principais elementos do processo de planejamento da mobilidade: i) redução da dependência de viagens motorizadas; ii) desenvolvimento dos meios não motorizados de transporte; iii) redução dos impactos ambientais da mobilidade urbana; e iv) promoção de integração entre modos de transporte.

Planejar meios para a população realizar viagens deveria ser um processo contínuo e envolveria o conhecimento da percepção dos possíveis usuários, principalmente para modos considerados não tradicionais em uma dada região. Nos últimos anos a bicicleta tem sido apontada como uma alternativa de transporte urbano que poderia trazer os seguintes benefícios: reduzir a dependência de veículos motorizados e consequentemente melhorar o fluxo do sistema de trânsito. Porém, é preciso incentivar o seu uso, melhorar a infraestrutura cicloviária e conforme, Rietveld e Daniel (2004), Lee et al. (2010), Pucher et al. (2010), Sherwin et al. (2011) e Lanzendorf e
Busch-Geertsema (2014) argumentam, é preciso conhecer o "lugar" da bicicleta no sistema de transporte urbano.

A percepção do uso da bicicleta como modo de transporte no Brasil segundo Hamer e Almeida (2015) é recente. Segundo estes autores a percepção envolve a possibilidade de substituição de veículos motorizados pela bicicleta em viagens urbanas. Por outro lado, esta percepção é acompanhada da presença ou visibilidade da possibilidade de usar a bicicleta diariamente. Segundo Silva Junior e Fontenele (2015) nos países onde o uso da bicicleta é considerado mais desenvolvido, tais como Holanda, França, Espanha e Dinamarca, a percepção de que a bicicleta poderia trazer benefícios gerais para uma dada região foi observada há algumas décadas e acompanhada pela aplicação de políticas claras de incentivo e informações claras e precisas sobre investimentos. Rocha (2015) salienta que na Suíça, país que possuí uma topografia relativamente acidentada, $23 \%$ das viagens diárias são realizadas por bicicleta e isso corrobora o fato que políticas e investimentos claros e precisos podem contribuir para incentivar e vencer barreiras ao uso do ciclismo como modo de transporte.

\section{OBJETIVO}

O objetivo deste estudo é apresentar uma análise da percepção dos usuários quanto aos modos de deslocamento urbano, principalmente a bicicleta e algumas medidas específicas de incentivo ao uso da bicicleta com base nesta percepção.

\section{FATORES QUE PODEM INFLUENCIAR NO USO DA BICICLETA}

As características individuais e os fatores socioculturais podem explicar muitas das questões relacionadas ao uso da bicicleta em áreas urbanas. As características individuais podem ser entendidas como: renda; sexo e atividade profissional exercida. Já os fatores socioculturais podem incluir: a imagem da bicicleta como modo de transporte em uma região; a herança cultural; a origem étnica e as 
preferências políticas (Rietveld e Daniel, 2004). Todos estes fatores combinados podem gerar impactos em termos de projeto, implantação e gerenciamento do ciclismo como modo de transportes. No Brasil, a bicicleta geralmente é vista como um instrumento de lazer e esporte. Esta peculiaridade pode estar fortemente vinculada àquelas regiões que têm o automóvel como um dos modos de transportes mais usados pela população. Isto foi evidenciado por Silva Junior e Fontenele (2015), que ao abordarem o ciclismo como modo de transporte em cidades que têm o automóvel com grande participação na distribuição modal de viagens diária, concluíram que a população da região de estudo percebe a bicicleta e a infraestrutura cicloviária como investimento em lazer e esporte.

O uso da bicicleta também pode estar associado à classe social e raça (cor da pele), conforme destacam Aldred e Jungnickel (2014). Segundo estes autores a bicicleta ainda sofre relativa marginalização, mesmo onde ela alcançou participação expressiva na matriz de viagens diária. Além disso, estes autores também reforçam que o uso do automóvel deixou de ser uma escolha racional por uma opção de transporte e passou a ser uma questão emocional.

Existem várias evidências a respeito do que poderia ou não tornar a bicicleta uma opção viável como modo de transporte. Porém, não há consenso sobre quais medidas poderiam motivar uma mudança de percepção em relação ao ciclismo. Alguns autores, como Pucher et al. (2010) e Yang et al. (2010) salientam que não existem comprovações de que ações isoladas podem aumentar o uso da bicicleta para realizar viagens urbanas. Estes autores definiram ações isoladas, como por exemplo: investimentos ou mudanças em infraestrutura ou políticas de incentivo. Por outro lado, Goeverden et al. (2015), argumentam que em locais que possuem pouca tradição de uso da bicicleta como modo de transporte e a infraestrutura é relativamente pobre, qualquer intervenção que estimule o uso do ciclismo pode gerar impactos diferenciados, porém geralmente estes impactos são positivos.

Autores como Rietveld e Daniel (2004);
Shannon et al. (2006); Lee et al. (2010); Pucher et al. (2010); Sherwin et al. (2011); Scheepers et al. (2013); Samyajit e Vasudevanb (2013); Aldred e Jungnickel, (2014) e Lanzendorf e Busch-Geertsema (2014) ressaltam que o emprego de políticas de investimento tanto em infraestrutura quanto em campanhas abrangentes para ampliar e consolidar a bicicleta como modo de transporte devem estar relacionadas à percepção da população.

\section{METODOLOGIA}

Para o desenvolvimento desta pesquisa realizou-se a adaptação de um questionário para investigar a percepção dos usuários e não usuários da bicicleta como meio de transporte, identificação dos locais onde seriam aplicados os questionários de pesquisa, gerar e analisar uma base de dados com as respostas aos questionários e simular um cenário de impacto considerando a percepção dos entrevistados e relacionar medidas de incentivo para motivar viagens por bicicleta. Sendo assim, a parte experimental desta pesquisa compreende três etapas: i) desenvolver um questionário para captar a percepção em relação ao uso do ciclismo como modo de transporte e o perfil socioeconômico dos entrevistados; ii) identificar o local para aplicação dos questionários; e iii) gerar um cenário que relacione a percepção dos entrevistados e o impacto que investimentos em infraestrutura e campanhas para motivar viagens por bicicleta poderiam ter caso as ciclovias e ciclofaixas incialmente construídas para lazer fossem conectadas entre si e a alguns locais de interesse da população.

O questionário usado para realizar as entrevistas foi adaptado de Stein et al. (2012), possui 18 perguntas e está dividido em três blocos: o primeiro bloco contém perguntas em relação à viagem que o entrevistado realiza regularmente (esquina mais próxima da origem e destino da viagem, horário de início e fim da viagem e motivo da viagem); no segundo bloco existem perguntas referentes à percepção do entrevistado em relação à bicicleta como modo de transporte; e no terceiro bloco as perguntas que caracterizam o perfil socioeconômico dos entrevistados. 


\subsection{CARACTERIZAÇÃO DO LOCAL DE ESTUTO}

A pesquisa foi desenvolvida na cidade de Londrina - Paraná. Em função de algumas peculiaridades esta cidade é um importante ambiente para pesquisar a percepção em relação ao uso da bicicleta como modo de transporte: é uma cidade de médio porte localizada em uma região metropolitana e que se desenvolveu fortemente nas últimas duas décadas devido a investimentos públicos e privados; tem uso intenso do automóvel em viagens urbanas; possui topografia relativamente acidentada; e conforme ressaltado por Silva Junior e Fontenele (2015), a infraestrutura cicloviária ainda é considerada e percebida como um investimento em lazer e esporte.

Na Tabela 1 são apresentadas informações relativas à cidade de Londrina e a Região Metropolitana de Londrina (RML). A principal atividade econômica da região é a agroindústria. Londrina tem se destacado também, nos setores da educação universitária, construção civil, comércio e tecnologia da informação (TI). Além disso, é a quarta cidade da região sul do Brasil em termos de população e nona em termos de PIB.

\subsection{AMOSTRA E PROCEDIMENTOS ADOTADOS PARA A COLETA DE DADOS}

Foram identificados dois locais do bairro Centro da cidade de Londrina para conduzir as entrevistas. Este bairro é densamente habitado, possui várias atividades que podem atrair e produzir viagens pelos principais modos de transporte urbano. Os locais de entrevista foram: Calçadão de Londrina (Avenida Paraná esquina com a Rua Pernambuco); e Terminal Central de Ônibus (esquinas das Ruas Professor João Cândido e Benjamin Constant). A pesquisa contou com a participação de oito entrevistadores que se revezaram em pelos menos uma dupla em cada local de pesquisa. As entrevistas foram realizadas no período da manhã e da tarde e de terça-feira a quinta-feira. Foram entrevistadas 83 pessoas durante o mês de outubro de 2015. Os entrevistadores eram alunos do curso de graduação em engenharia civil da Universidade Estadual de Londrina (UEL). Com relação à quantidade de entrevistados, ficou definido que o grupo não seria tratado como uma amostra representativa da população da cidade. Esta decisão é justificada pelo objetivo principal do trabalho, que é testar e apresentar um procedimento a ser aplicado para casos muito específicos de planejamento de transportes.

\begin{tabular}{lccc}
\hline \multicolumn{4}{c}{ TABELA 1: Dados socioeconômicos de Londrina e demais municípios da RML. } \\
\hline \multicolumn{1}{c}{ Local } & População & IDH & PIB Per capita (dólares americanos) \\
\hline Londrina & $553.393^{1}$ & $0,778^{1}$ & $\$ 9.146,00^{3}$ \\
Demais municípios da RML & $516.607^{1}$ & $0,713^{2}$ & $\$ 7.162,00^{3}$ \\
Brasil & $204.000 .000^{1}$ & 0,699 & $\$ 8.967,70^{3}$
\end{tabular}

FONTE: Instituto Brasileiro de Geografia e Estatística (IBGE). 1 População residente e índice de desenvolvimento humano (IDH) em 21/09/2016 segundo IBGE. 2 Valor médio do IDH - para os demais municípios da RML segundo o IBGE. 3 Conversão Real para Dólar do PIB per capita em 21/09/2016 - Cotação do dólar: Banco Central do Brasil. 


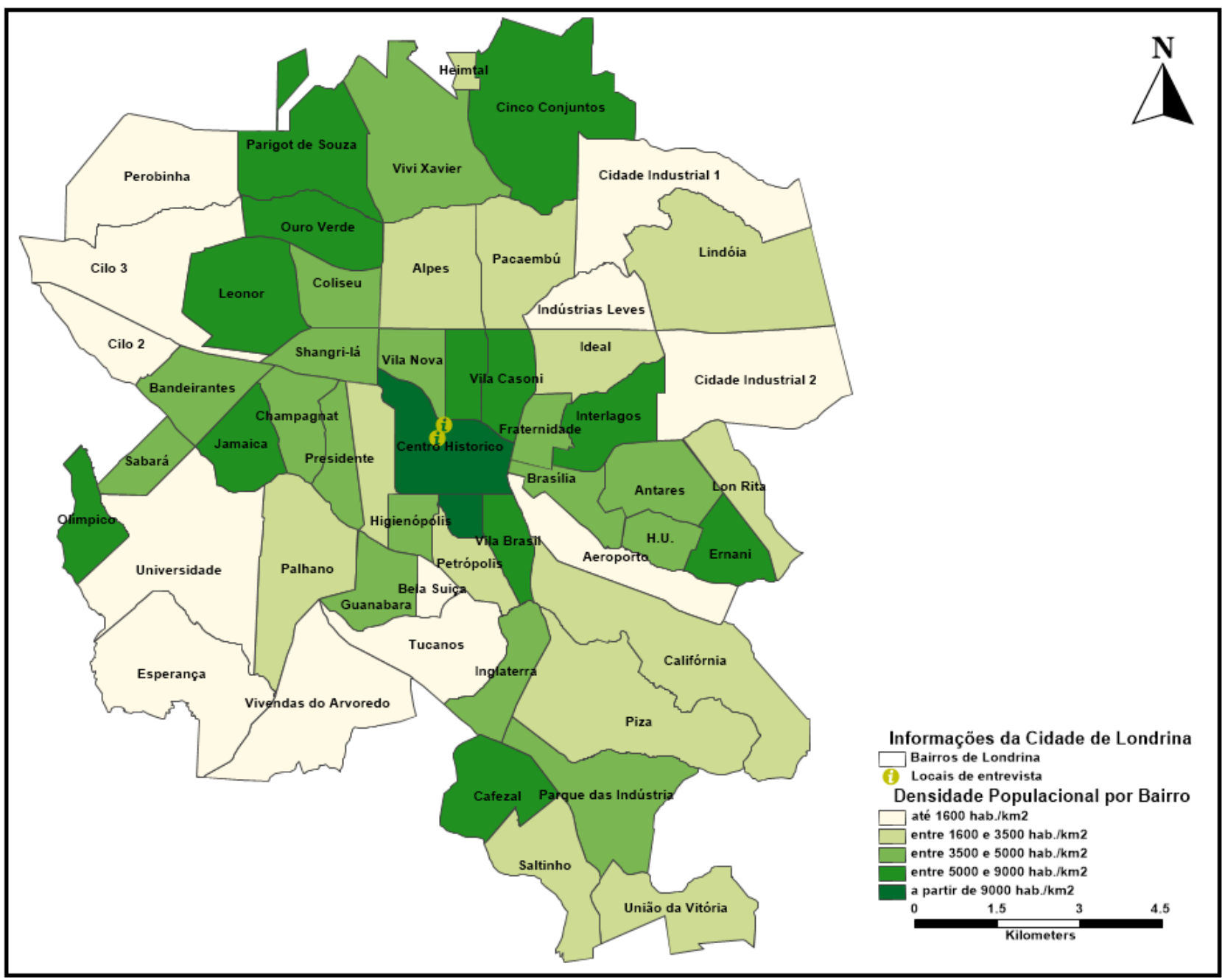

FIGURA 1: Bairros, locais de entrevista e densidade populacional por bairro na cidade de Londrina. FONTE: Autoria Própria.

Para o caso específico desta pesquisa também ficou definido que seriam considerados usuários da bicicleta como modo de transporte os entrevistados que utilizam a bicicleta para ir ao trabalho, a escola, a universidade, fazer compras, ou usam a bicicleta para fazer transporte de mercadorias. Aqueles que não usam a bicicleta em nenhuma das situações citadas anteriormente foram considerados não usuários. Na Figura 1 estão representados os bairros da cidade de Londrina, os locais de entrevista e a densidade populacional por bairro da cidade.

\subsection{PROCEDIMENTOS UTILIZADOS PARA A ANÁLISE DOS DADOS}

A partir da percepção dos entrevistados em relação ao uso da bicicleta como modo de transporte foi possível simular um cenário sobre o uso da bicicleta com base nas respostas dos entrevistados. Este cenário relaciona esta percepção e o impacto que possíveis investimentos para conectar entre si e a alguns locais de interesse da população as ciclovias que foram incialmente construídas para lazer. A simulação do cenário foi feita a partir de uma base de dados que inclui as informações relativas às viagens dos entrevistados (coordenadas geográficas de origem e destino, horário e motivo das viagens), as respostas referentes à percepção em relação à bicicleta e as características socioeconômicas dos entrevistados. Em seguida foi feito o cruzamento das informações da base de dados a partir dos seguintes critérios para simular o cenário de impacto: $i$ ) entrevistados dispostos a trocar seu modo atual para a bicicleta; ii) entrevistados favoráveis a bicicleta; e iii) entrevistados dispostos a usar as ciclovias de lazer para realizar viagens diárias. A identificação da origem e destino de cada entrevistado foi obtida no 
Google Earth com base na esquina mais próxima do início e fim da viagem. Este procedimento possibilitou identificar as distâncias de viagem com base na atual rede de vias da cidade de Londrina por meio de um sistema de informações geográficas. Com relação à questão das ciclovias de lazer apontada por Silva Junior e Fontenele (2015), no questionário de pesquisa os entrevistados foram perguntados se eles usariam as vias para bicicleta que são destinadas ao lazer para fazer viagens ao longo da semana para ir ao trabalho, a escola, ao banco, ao shopping, ao supermercado. Foi ressaltado que estas vias seriam devidamente conectadas entre si e a pontos de interesse (escolas, universidades e faculdades, shopping centers etc.). Vale ressaltar que as vias de lazer para bicicleta em Londrina são relativamente planas, pois foram construídas às margens dos rios e lagos da cidade, conforme já apresentado em Silva Junior e Fontenele (2015).

\section{RESULTADOS E DISCUSSÕES}

Os resultados deste estudo estão apresentados nesta seção conforme a seguinte ordem: i) informações sobre o perfil socioeconômico dos entrevistados; ii) características dos padrões de viagens dos entrevistados; e iii) simulação de um cenário que relaciona a percepção dos entrevistados e o impacto que possíveis investimentos e campanhas teriam sobre o uso da bicicleta.

\subsection{PERFIL SOCIOECONÔMICO DOS ENTREVISTADOS}

Na Tabela 2 são apresentadas informações socioeconômicas dos entrevistados que foram solicitadas no questionário de pesquisa. Conforme os dados da Tabela 2,75\% dos entrevistados possui idade entre 18 e 55 anos. Segundo o IBGE (2016) $67 \%$ da população do município de Londrina também compreende estas faixas etárias. Com relação à renda a maior parte dos entrevistados situa-se na faixa de renda entre 1 a 5 salários mínimos (80\%) e segundo o IBGE (2016) 55\% da população do município está nestas faixas de renda.

\subsection{PADRÕES DE VIAGENS DOS ENTREVISTADOS}

Nesta seção são apresentadas as características das viagens realizadas pelos entrevistados, tais como: distribuição modal; períodos de realização das viagens; propriedade de veículos; principais problemas encontrados durante suas viagens e distância de viagem.

Na Figura 2 está representada a origem e o modo de transporte dos entrevistados em suas viagens. Conforme pode ser observado não existem entrevistados usuários da bicicleta. Nenhum dos entrevistados declarou usar a bicicleta como meio de transporte apesar de uma parcela da amostra ser proprietária de bicicleta.

\section{TABELA 2: Dados socioeconômicos da amostra.}

\begin{tabular}{lccccccc}
\multicolumn{1}{c}{ Dados } & \multicolumn{7}{c}{ Valores } \\
\hline Faixa Etária & $<18$ & 18 a 25 & 25 a 35 & 35 a 45 & 45 a 55 & 55 a 65 & $>65$ \\
(anos) & $8 \%$ & $30 \%$ & $10 \%$ & $13 \%$ & $22 \%$ & $7 \%$ & $10 \%$ \\
& & & & & & & \\
Faixa de Renda & Até um & 1 a 2 & 2 a 5 & Acima de 5 \\
(salário mínimo) & $12 \%$ & $41 \%$ & $39 \%$ & $8 \%$ \\
\hline
\end{tabular}


Conforme a Figura 3 a maioria dos entrevistados utiliza em suas viagens o transporte motorizado e os modos carro e ônibus coletivo são os mais utilizados. Existe também uma parcela significativa de entrevistados que faz viagens a pé. No período da manhã existe uma distribuição maior das viagens entre os modais. Por outro lado, nos períodos da tarde e da noite o modal automóvel e ônibus e a pé e ônibus são respectivamente os mais utilizados. Esta distribuição modal da amostra parece refletir os motivos de viagem da amostra que são: trabalho, compras e estudo.

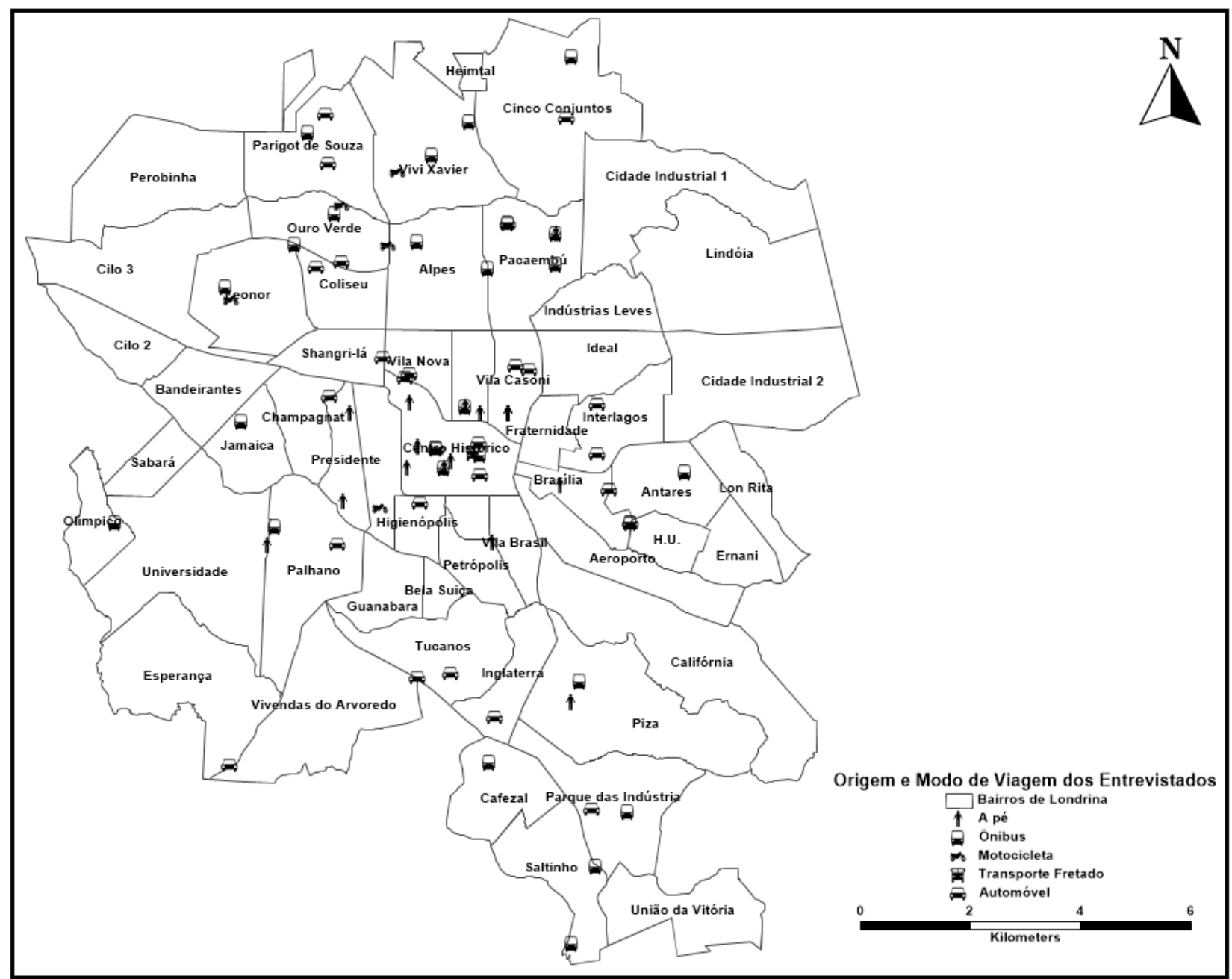

FIGURA 2: Origens dos entrevistados por bairro e modo de viagem. FONTE: Autoria Própria.

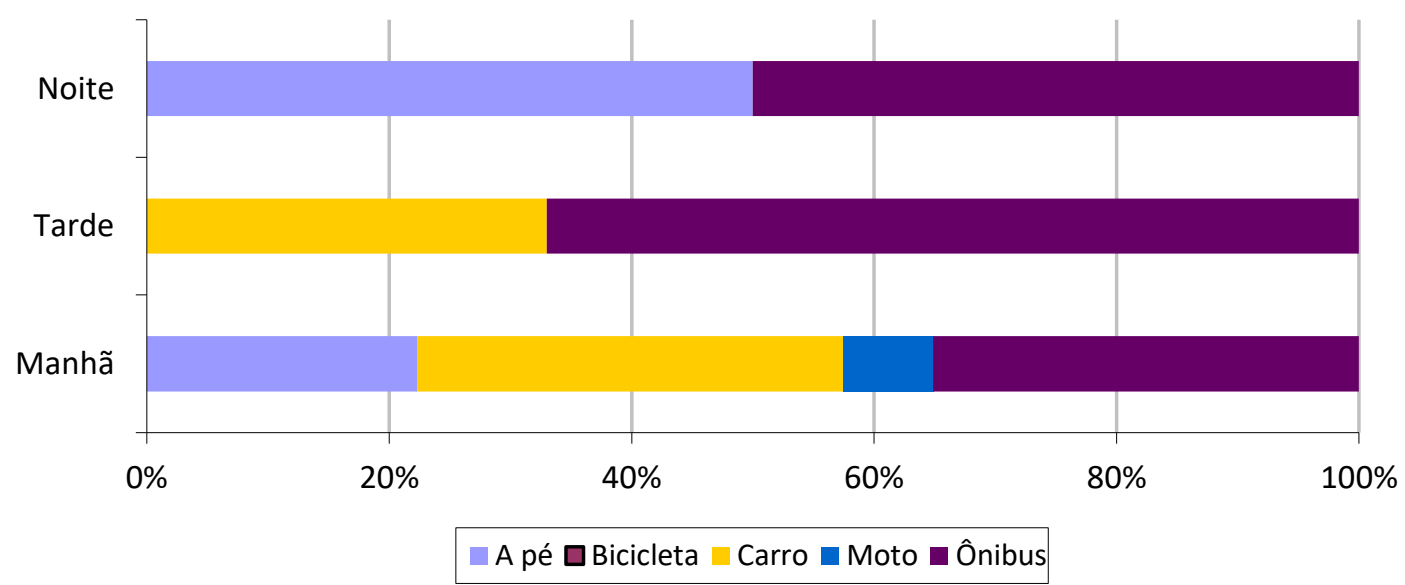

FIGURA 3: Matriz modal de viagens da amostra de entrevistados. FONTE: Autoria Própria. 
$\mathrm{Na}$ Figura 4 estão as porcentagens de entrevistados segundo a propriedade de veículos. Pode-se observar que $73 \%$ dos entrevistados são proprietários de automóvel e que 31\% possuem bicicleta. Os entrevistados proprietários de bicicleta declararam que o principal uso deste veículo é para prática de pequenos passeios aos finais de semana e feriados e esporte no início da manhã, final da tarde e parte da noite. Afirmaram que usam a bicicleta para estas atividades porque percebem que esta é a função da bicicleta na cidade de Londrina. Além disso, afirmaram que algumas vezes participam de passeios ciclísticos promovidos por entidades públicas ou privados. Esta questão da promoção de passeios ciclísticos foi abordada por Silva Junior e Fontenele (2015), que relatam esta prática na cidade de Londrina e que parece existe uma vinculação desta prática como uma política de incentivo ao uso da bicicleta como modo de transporte.

Cada entrevistado foi solicitado a indicar qual o principal problema que encontrava regularmente em suas viagens diárias até o dia da entrevista. Conforme a Figura 5 pode-se observar que lotação (39\%) e atraso dos ônibus (25\%), congestionamento nas vias (39\%) e falta de estacionamentos públicos (23\%) são os problemas mais indicados pelos entrevistados. Estes problemas parecem refletir a distribuição modal dos entrevistados (Figura 3), pois os dois principais modos de viagens são o automóvel e o ônibus coletivo. Por outro lado, existe uma parcela de entrevistado que indicou dificuldades em cruzar rotatórias (22\%) e falta de segurança nas caminhadas $(17 \%)$ como problemas em suas viagens. Vale ressaltar que $95 \%$ dos entrevistados que indicaram estes problemas fazem suas viagens pelo modo a pé. Os demais realizam viagens de automóvel e ônibus.

Com base na origem e destino das viagens e a rede de vias da cidade de Londrina foi possível estimar a distância de viagem de cada entrevistado. Na Figura 6 estão representados os porcentuais de entrevistados conforme a faixa de distância de viagem. Observa-se que 52\% dos entrevistados fazem viagens com mais de $4 \mathrm{~km}$ e uma parcela de $48 \%$ faz viagens de até $4 \mathrm{~km}$.

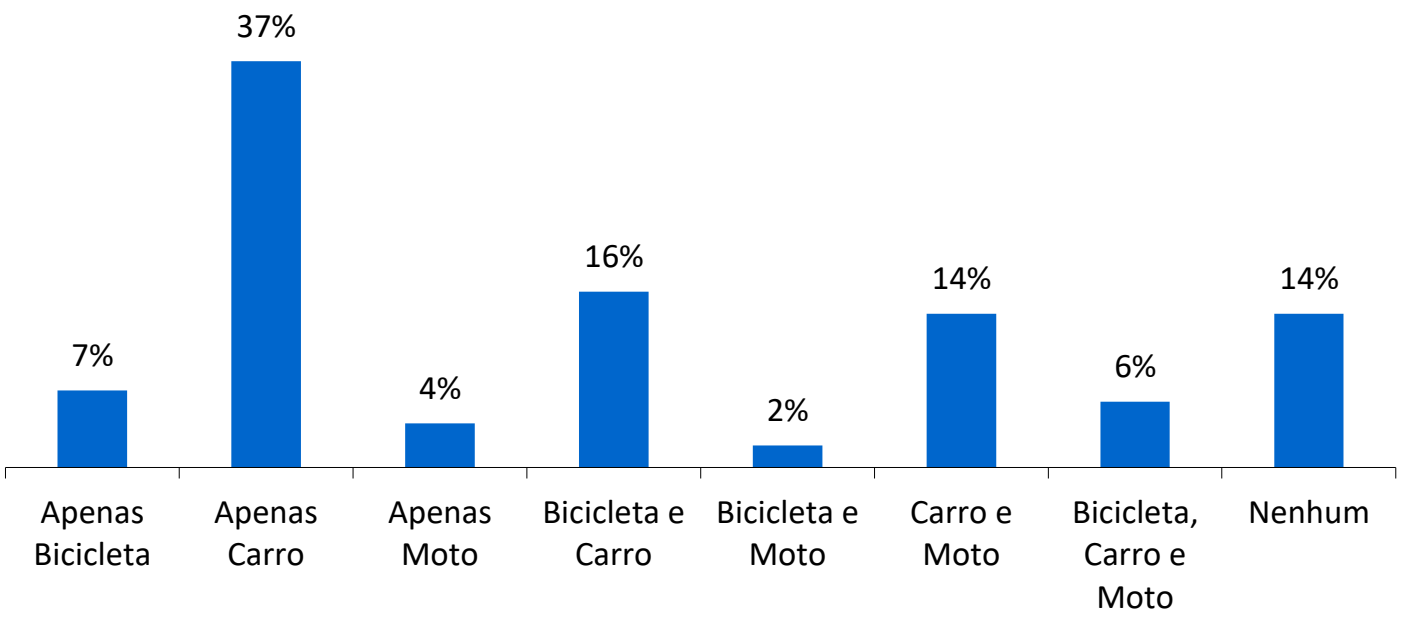

FIGURA 4: Porcentual de entrevistados conforme a propriedade de veículos. FONTE: Autoria Própria. 


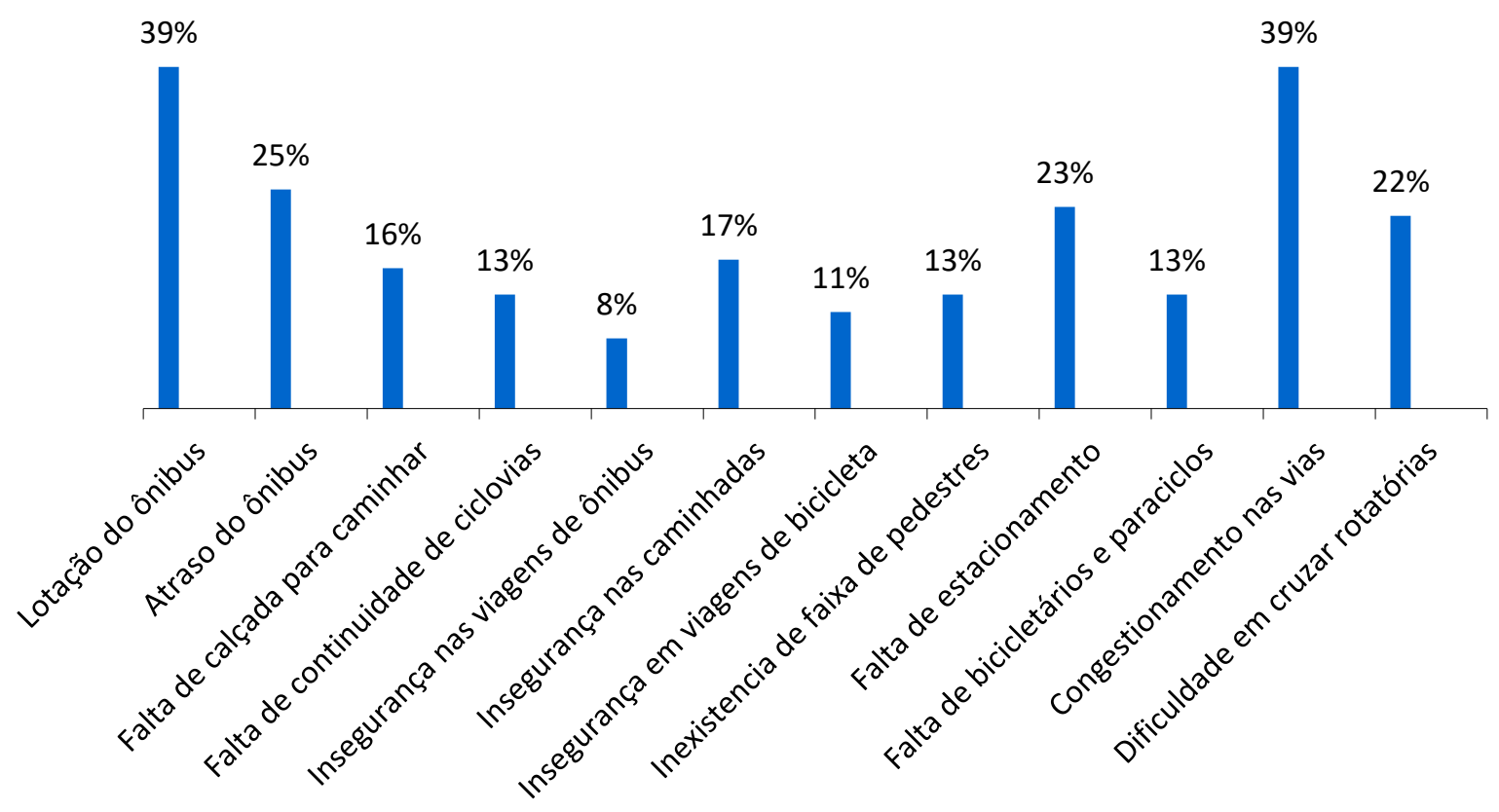

FIGURA 5: Porcentual de entrevistados e os problemas encontrados em suas viagens. FONTE: Autoria Própria.

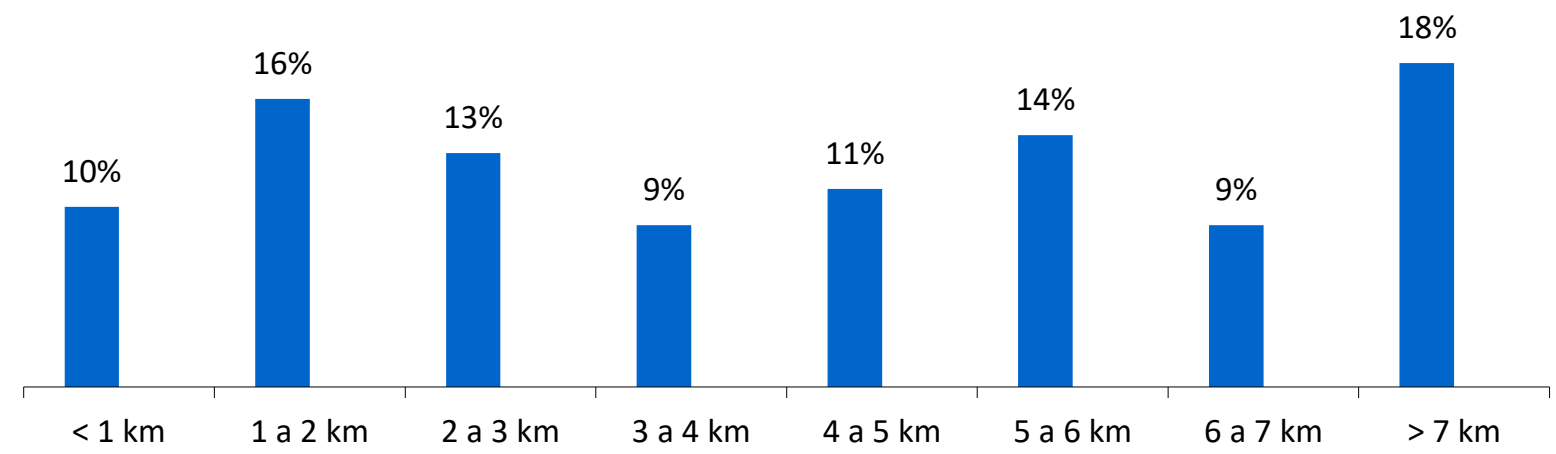

FIGURA 6: Porcentual de entrevistados por faixa de distância de viagem.

FONTE: Autoria Própria.

\subsection{SIMULAÇÃO DE CENÁRIO QUE RELACIONA A PERCEPÇÃO DOS ENTREVISTADOS E O IMPACTO DOS INVESTIMENTOS EM CAMPANHAS SOBRE O USO DA BICICLETA}

Um dos objetivos de identificar a percepção dos cidadãos em relação a determinado produto ou serviço é respaldar políticas e investimentos que possam motivar o uso deste produto ou serviço. No setor de transporte urbano a percepção dos usuários pode contribuir para planejar medidas de incentivo a determinado modo de transporte, principalmente medidas que incentivem a troca de modos motorizados individuais (carro e motocicleta) por modos motorizados coletivos (ônibus) e não motorizados (a pé e bicicleta). Nesta seção será apresentada a simulação de um cenário que leva em consideração a percepção dos entrevistados deste estudo e as medidas que poderiam estar associadas a este cenário para motivar o uso da bicicleta como modo de transporte urbano. Em função do número de entrevistados ser relativamente pequeno é importante ressaltar que a finalidade deste estudo é testar um procedimento que pudesse ser reproduzido de forma prática e rápida e para casos específicos de planejamento pontuais de transportes, como por exemplo: projeto e implantação de uma conexão entre duas ciclovias 
num bairro específico de uma cidade.

Uma questão importante sobre as políticas de incentivo ao uso da bicicleta está relacionada à sua aceitação e a possibilidade de troca do atual modo de viagem para a bicicleta por parte dos moradores de uma determinada região. Ao serem abordados os entrevistados deste estudo foram perguntados sobre a sua opinião em relação ao uso da bicicleta como modo de transporte. No questionário de pesquisa há quatro alternativas de resposta a esta pergunta: favorável, indiferente; desfavorável e outro. Pode-se observar na Figura 7 que $83 \%$ são favoráveis ao uso da bicicleta como modo de transporte. Existe uma parcela de $16 \%$ que é indiferente e apenas 1\% é desfavorável.
Para complementar a informação da percepção em relação ao uso da bicicleta como modo de transportes, na Figura 8 tem-se a opinião e o modo de viagem usado diariamente por cada entrevistado. Observar-se que a maioria dos entrevistados é favorável ao uso da bicicleta independente do modal atualmente usado para realizar viagens diárias. Existe uma parcela de entrevistados que é indiferente, a exceção é para aqueles que usam a motocicleta, os quais são $100 \%$ favoráveis ao uso da bicicleta. No caso dos usuários do carro há uma parcela de $4 \%$ que são desfavoráveis às bicicletas como modo de transporte.

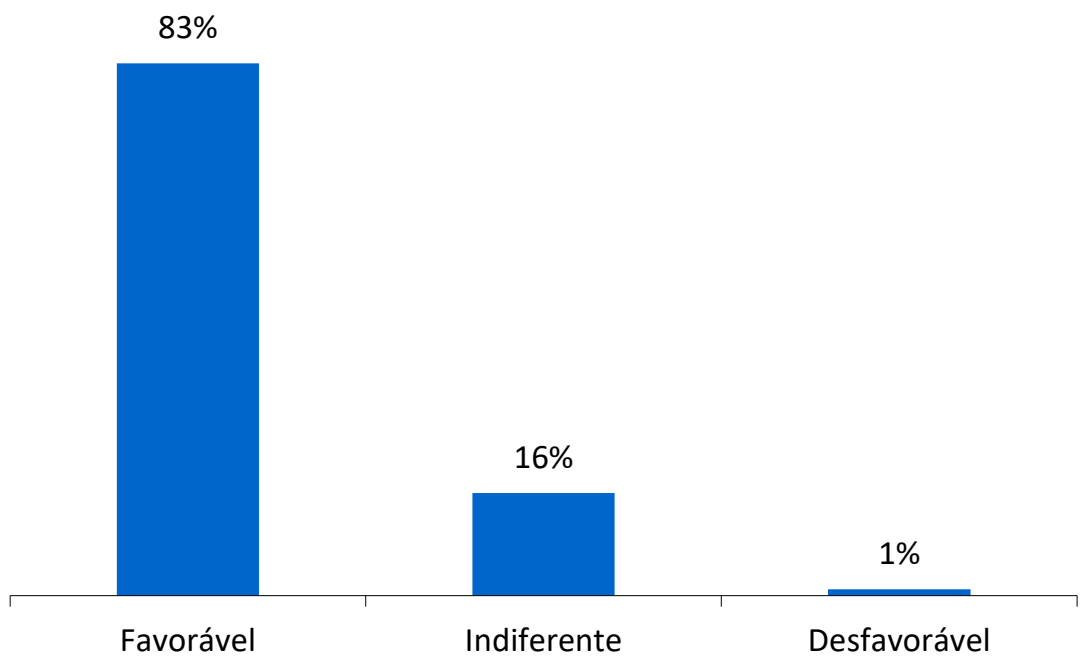

FIGURA 7: Opinião dos entrevistados sobre o uso da bicicleta como modo de transporte. FONTE: Autoria Própria.

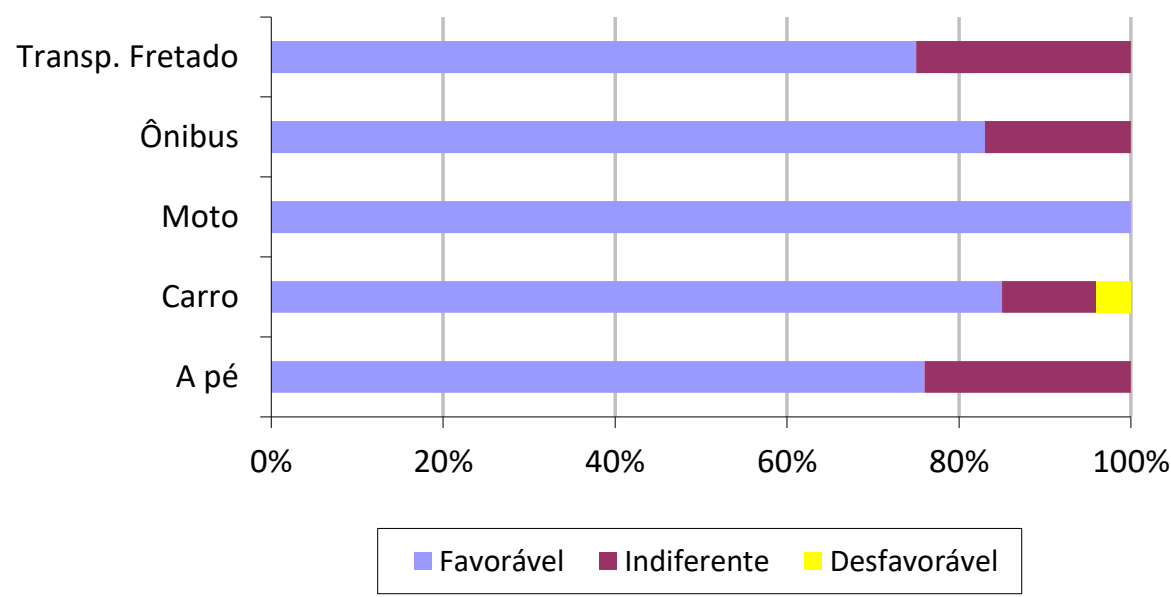

FIGURA 8: Opinião conforme o modo de viagem usado diariamente por cada entrevistado. FONTE: Autoria Própria. 
Em relação à possibilidade de trocar o atual modo de transporte tem-se que $53 \%$ dos entrevistados disseram que gostariam de trocar seu atual modo de transporte e $47 \%$ não gostariam de trocar. Entre aqueles que gostariam de trocar seu modo de transporte $16 \%$ mudariam para a bicicleta, conforme a Figura 9 . Por outro lado, $43 \%$ gostariam de usar o automóvel em suas viagens diárias. Ainda assim, a bicicleta mostrou-se mais promissora que o ônibus e a caminhada.

Autores como Rietveld e Daniel (2004) e Aldred e Jungnickel (2014) relatam que diversos fatores podem influenciar o uso da bicicleta como modo de transportes urbano. Entre estes fatores eles citam o preconceito ou marginalização. Para entender esta questão os entrevistados foram perguntados em relação a três aspectos: i) se há preconceito em relação ao uso da bicicleta na cidade; ii) se o uso do automóvel representa status; e iii) se eles usariam as vias destinadas ao lazer para realizar viagens durante a semana para ir ao trabalho, ao local de estudo e/ou fazer compras usando uma bicicleta. Na Tabela 3 tem-se a porcentagem de respostas para estas três questões. Como se pode observar na Tabela 3 a maioria dos entrevistados disse que não existe preconceito em relação ao uso bicicleta. Por outro lado, vale ressaltar que entre os entrevistados não há usuários da bicicleta como modo de transporte. Desta forma, as respostas podem ser entendidas sob os seguintes aspectos: i) a maioria dos entrevistados não tem preconceito em relação ao uso da bicicleta; e/ou ii) a maioria não vê preconceito em relação aos usuários da bicicleta por parte de outras pessoas. Ainda com base na Tabela 3 pode-se observar que a maioria dos entrevistados respondeu que o uso do automóvel representa status para o seu condutor perante a sociedade. Neste caso vale ressaltar que $73 \%$ dos entrevistados são proprietários de automóvel (ver Figura 4).

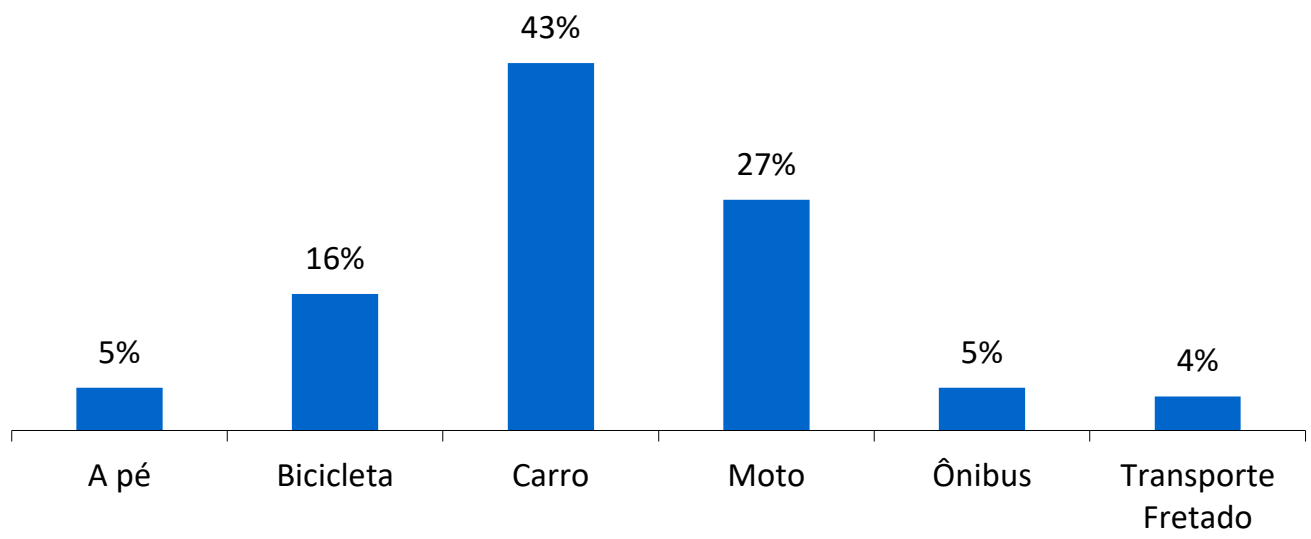

FIGURA 9: Porcentagem de entrevistados que indicou mudar de modo e para qual modo gostaria de mudar.

FONTE: Autoria Própria.

TABELA 3: Aspectos relacionados ao uso da bicicleta.

\begin{tabular}{|c|c|c|}
\hline Perguntas & Sim & Não \\
\hline Há preconceito em relação ao uso da bicicleta na cidade? & $40 \%$ & $60 \%$ \\
\hline O uso do automóvel representa status perante a sociedade? & $66 \%$ & $34 \%$ \\
\hline $\begin{array}{l}\text { Você usaria as ciclovias destinadas ao lazer para realizar viagens durante } \\
\text { a semana para ir ao trabalho, ao local de estudo e/ou fazer compras } \\
\text { usando uma bicicleta? }\end{array}$ & $48 \%$ & $52 \%$ \\
\hline
\end{tabular}


Conforme demonstrado por Silva Junior e Fontenele (2015) a cidade de Londrina possui algumas ciclofaixas e ciclovias que estão no entorno de locais de lazer. Desta forma, é interessante saber a opinião dos entrevistados se eles usariam esta infraestrutura caso ela possuísse conectividade entre si, estivesse em local relativamente plano e fosse estrategicamente expandida de forma a alcançar pontos de interesse da população, tais como: locais com grande oferta de emprego; áreas de comércio; centro administrativo da cidade (prefeitura, câmara municipal, fórum, etc.) ou polos geradores de viagens (universidades, escolas, ginásios de esporte etc.). Com base nas informações da Tabela 3, observa-se que $48 \%$ dos entrevistados responderam que usariam as vias para bicicleta, que foram inicialmente construídas para lazer, para ir ao trabalho, a escola, ao banco, ao shopping e ao supermercado. Desde que estas vias atendessem aos requisitos já mencionados anteriormente (conectividade entre si e a pontos de interesse e fossem relativamente planas).

Para captar a percepção em relação aos atributos relacionados aos modos de transporte urbano e principalmente ao uso da bicicleta, foi pedido aos entrevistados que indicassem quais atributos eles associavam a cada modo de transporte a partir de uma lista de modos e características. Na Figura 10 são apresentados os atributos que foram relacionados a cada modo de transporte usado em viagens urbanas e o porcentual de entrevistados que indicou esta relação. Com relação à bicicleta, observa-se que $57 \%$ dos entrevistados a consideram um modo de transporte não poluente, $48 \%$ de baixo custo e $37 \%$ não motorizado. Por outro lado, apenas $2 \%$ acham o uso da bicicleta seguro. Isto evidencia que uma parcela razoável dos entrevistados conhece as características básicas da bicicleta como um modo de deslocamento diário.

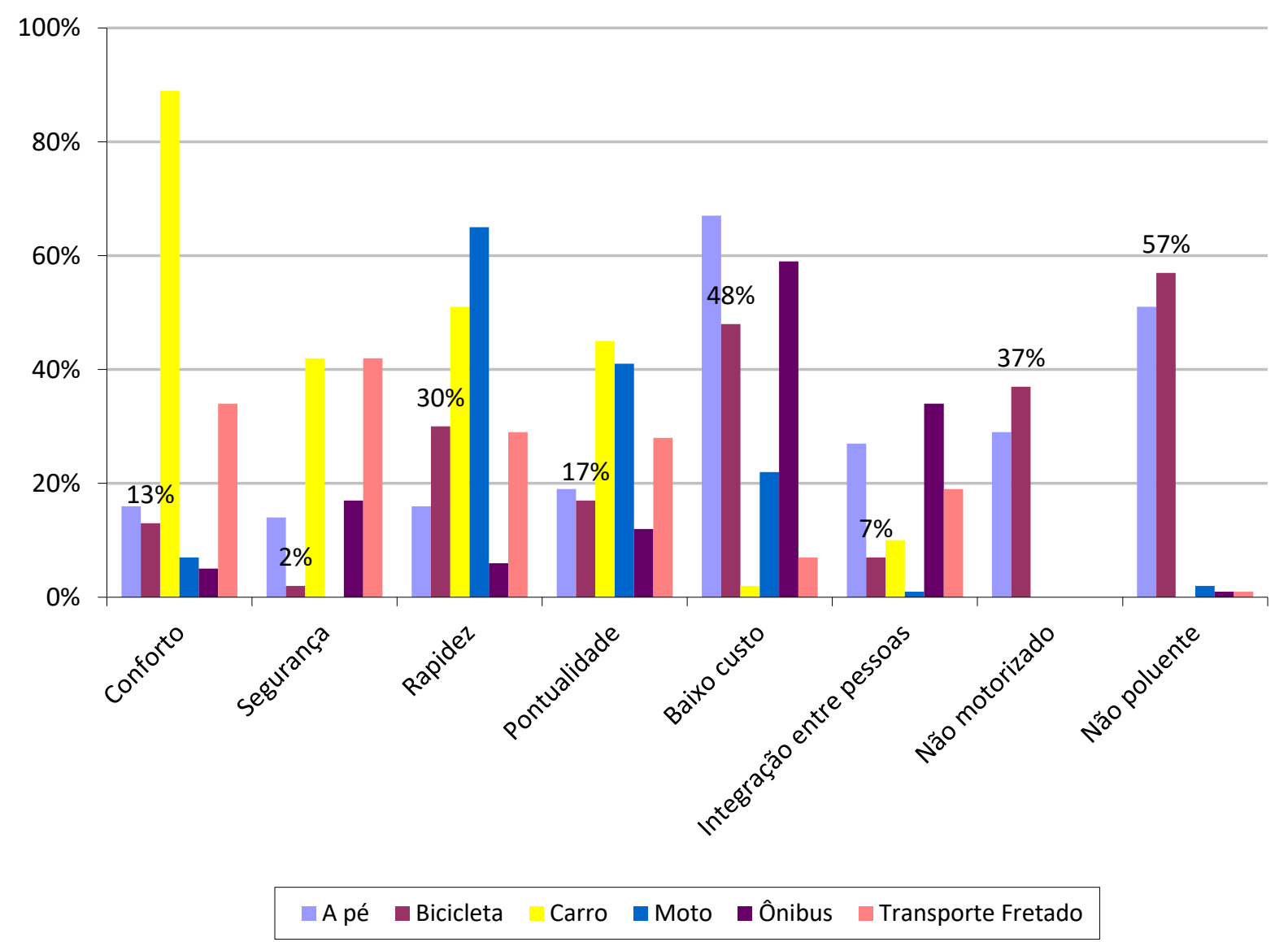

FIGURA 10: Porcentual de entrevistados e atributos relacionados aos modos de viagem. FONTE: Autoria Própria. 
Uma das principais limitações do uso da bicicleta é à distância de viagem. Para o caso específico deste estudo, observa-se que $39 \%$ dos entrevistados fazem viagens que estão na faixa de até $3 \mathrm{~km}$ em um único sentido (ver Figura 6 ). Para o caso de viagens pendulares, por exemplo, casatrabalho ou casa-estudo, estes entrevistados poderiam ser considerados potenciais usuários da bicicleta como modo de transporte.

Com base no exposto até o momento e para o caso específico deste estudo $8,4 \%$ dos entrevistados estão dispostos a fazer viagens diárias por bicicleta pelas vias que foram inicialmente projetadas e construídas para prática de lazer desde que estas estejam conectadas entre si e com outras áreas de interesse. Para gerar este cenário a partir da amostra de estudo foram considerados os seguintes critérios: i) todos estão dispostos a trocar seu modo atual para a bicicleta; ii) todos são favoráveis a bicicleta e iii) todos estão dispostos a usar as ciclovias de lazer para realizar viagens diárias (conforme já abordado). Além disso, outras questões podem contribuir para a quantificação deste cenário: os entrevistados conhecem os atributos da bicicleta (ver Figura 10) e a maioria reconhece que não há preconceito em relação à bicicleta (ver Tabela 3). Desta forma, pode-se inferir que existe uma parcela de entrevistados que se for incentivada poderia usar a bicicleta como modo de transporte. Desta forma, podem ser associadas a este cenário duas medidas para incentivar viagens diárias por bicicleta: i) realizar investimentos que conectassem e ampliassem as ciclovias de esporte e lazer já existentes aos locais de interesse da população; e ii) conduzir campanhas de divulgação sobre o propósito desses investimentos a fim de motivar a população a usar a bicicleta em viagens diárias.

\section{CONCLUSÕES}

Para o caso específico deste estudo o procedimento testado para obter a percepção de um grupo de entrevistados a respeito do uso da bicicleta como modo de transporte parece ser relativamente prático e rápido em situações específicas de planejamento de transportes. Foi possível construir uma base de dados e gerar uma série de informações para respaldar a tomada de decisões em relação ao uso da bicicleta como modo de transporte, como por exemplo: a maioria dos entrevistados é favorável ao uso da bicicleta como modo de transporte; não há preconceito em relação ao ciclismo; o ciclismo é visto principalmente como atividade de lazer e esporte; cerca de 1/3 da amostra possui e usa a bicicleta para atividades de lazer e/ou esporte e o carro ainda representa status perante a sociedade para o seu condutor. Isto pode ser uma evidencia de que se a bicicleta receber o devido tratamento em termos de políticas de incentivo ao seu uso ela poderá torna-se viável para viagens urbanas no médio e longo prazo.

Com relação à geração de um cenário que vinculasse a percepção dos entrevistados e medidas de incentivo ao uso da bicicleta como modo de transporte, o procedimento adotado permitiu chegar a uma porcentagem de $8,4 \%$ de entrevistados como potenciais usuários da bicicleta. Isto seria possível, caso fossem realizados investimentos para conectar as vias construídas para lazer entre si e conectar essas vias a alguns locais de interesse da população. De um modo geral para o caso específico deste estudo o procedimento testado permite concluir que a percepção dos entrevistados em relação à bicicleta como modo de transporte na área urbana da cidade de Londrina ainda é tímida. Porém, investimentos em infraestrutura cicloviária, políticas claras e campanhas que divulgassem o propósito dos investimentos poderiam tornar a bicicleta uma alternativa viável para viagens diárias.

\section{AGRADECIMENTOS}

Os autores agradecem a Universidade Estadual de Londrina pelo suporte material e a Fundação Araucária pela concessão de bolsa de iniciação científica. 


\section{REFERÊNCIAS BIBLIOGRÁFICAS}

Abreu, T. P.; L. Cardoso; L. Kelli de Oliveira; C. Lobo; L. M. B. Santos; L. A. P. Almeida; R. M. C. Alves; F. M. Coelho; R. M. Barros; E. Laizo Neto e B. G. dos Santos Costa (2015) A bicicleta como meio de transporte integrado a terminais de ônibus: considerações sobre o caso do terminal ressaca, contagem (Minas Gerais). Anais do XXIX Congresso de Pesquisa e Ensino em Transportes, ANPET, Ouro Preto, v. 1, 2015, p. 1762-1773.

Aldred, R. e K. Jungnickel (2014) Why culture matters for transport policy: the case of cycling in the UK. Journal of Transport Geography, v. 34, n. 1, p. 78-87. DOI: 10.1016/j.jtrangeo.2013.11.004.

Goeverden, K.; T. S. Nielsen; H. Harder; R. Nes (2015) Interventions in bicycle infrastructure, lessons from Dutch and Danish cases. Transportation Research Procedia. v.1, n. 10, p. 403-412. DOI: 10.1016/j.trpro.2015.09.090.

Hamer, L. J. e C. F. Almeida. O olhar do ciclista sobre o "lugar" e a "paisagem urbana", em busca da identificação dos pontos de atratividade para as intervenções urbanas. Anais do XXIX Congresso de Pesquisa e Ensino em Transportes, ANPET, Ouro Preto, v. 1, 2015, p. 1954-1970.

Lanzendorf, M. e A. Busch-Geertsema (2014) The cycling boom in large German cities - Empirical evidence for successful cycling campaigns. Journal of Transport Policy, v. 36, n.1, p. 26-33. DOI: 10.1016/j.tranpol.2014.07.003.

Lee, I.; H. Park e K. Sohn (2010) Increasing the number of bicycle commuters. Proceedings of The Institution of Civil Engineers - Transport, v. 165, n. 1, p. 63-72.

BRASIL - MINISTÉRIO DAS CIDADES (2007) Guia PlanMob: Construindo a Cidade Sustentável. Disponível em http://www.cidades.gov.br/images/stories/ArquivosSNH/ArquivosPDF/Livro-Plano-Mobilidade.pdf.

Pucher, J.; J. Dill e S. Handy (2010) Infrastructure, programs, and policies to increase bicycling: An international review. Journal of Preventive Medicine, $v$. 50, n. $1, \quad$ p. S106-S125. DOI: 10.1016/j.ypmed.2009.07.028.

Rietveld, P. e V. Daniel (2004) Determinants of bicycle use: do municipal policies matter? Journal of Transportation Research Part A, v. 38, n. 1, p. 531-550. DOI: 10.1016/j.tra.2004.05.003.

Rocha, J. Uso da bicicleta vem sendo incentivado como alternativa de transporte. Revista Bicicleta. Disponível em

http://www.revistabicicleta.com.br/bicicleta_noticia.ph p?uso_da_bicicleta_vem_sendo_incentivado_com_alternativa_de_transporte\&id=31574. 2015.
Samyajit, B. e V. Vasudevanb (2013) Effect of bicycle friendly roadway infrastructure on bicycling activities in urban India. Procedia - Social and Behavioral Sciences. v. 1 n. 104, p. 1139-1148. DOI: 10.1016/j.sbspro.2013.11.210

Scheepers, E.; W. Wendel-Vos; E. Kempen; L. I. Panis; J. Maas; H. Stipdonk; M. Moerman; F. Hertog; B. Staatsen; P. Wesemael e J. Schuit (2013) Personal and environmental characteristics associated with choice of active transport modes versus car use for different trip purposes of trips up to $\mathbf{7 . 5}$ kilometers in the Netherlands. PLOS ONE, v. 8, n. 9, p. e73105. DOI: 10.1371/journal.pone.0073105

Sherwin, H.; G. Parkhurst; D. Robbins e I. Walker (2011) Practices and motivations of travellers making rail cycle trips. Proceedings of the Institution of Civil Engineers - Transport, v. 164, n. 3, p. 189-197.

Shannon, T.; B. Giles-Corti; T. Pikora; M. Bulsara; T. Shilton e F. Bull (2006) Active commuting in a university setting: assessing commuting habits and potential for modal change. Transport Policy, v. 13, n. 3, p. 240-253. DOI: 10.1016/j.tranpol.2005.11.002.

Silva Junior, C. A. P e H. B. FONTENELE. (2015) Ciclismo como um modo de transporte em cidades de pequeno $\mathrm{e}$ médio porte. Anais do XXIX Congresso de Pesquisa e Ensino em Transportes, ANPET, Ouro Preto, v. 1, p. 17181729 .

Stein, P. P.; A. N. Rodrigues da Silva e C. A. P. da Silva Junior (2012) Impactos nas distâncias de caminhada decorrentes de acessos exclusivos para pedestres em um campus universitário. Revista Paranoá, v. 1, n. 6, p. 113-121.

Yang, L.: S. Sahlqvist; A. McMinn; S. J. Griffin e D. Ogilvie (2010) Interventions to promote cycling: Systematic review. BMJ 341, c5293. 